Motrivivência $\quad$ Ano XX, $\quad$ No 30, P. 44-60 $^{\circ}$ Jun./2008

\title{
A Educação Física frente a temática ambiental: alguns elementos teórico-metodológicos
}

\section{Physical education in the face of environmental issues: some theoretical and methodological elements}

\author{
Fabiano Weber da Silva?' \\ Ana Márcia Silva? \\ Humberto Luís de Deus Inácio 3
}

\begin{abstract}
Resumo Abstract
Neste ensaio, argumentamos que a crise ambiental diz respeito a todos e a tudo que vimos desenvolvendo civilizatoriamente e deve, por isso e por suas decorrências futuras, ser problematizada no âmbito da educação formal. Com esse objetivo, indicamos alguns elementos teóricometodológicos para subsidiar experiências pedagógicas a serem desenvolvidas com a partir da temática ambiental, no interior da disciplina curricular obrigatória Educação Física.

Palavras Chaves: Educação Física; Educação Ambiental; Prática Pedagógica; Experiência.
\end{abstract}

\footnotetext{
Mestre em Educação Física (UFSC). Contato: fabianoweber@sesc-sc.com.br

Doutora em Ciências Sociais (UFSC). Contato: amarciasi@gmail.com

Doutor em Educação (UFSC). Contato: betoinacio@gmail.com
} 


\section{Considerações Iniciais}

A questão ambiental ocupa, cada vez mais, a agenda política, assim como o espaço midiático e o imaginário social, especialmente pelas decorrências dramáticas dos eventos naturais que são a parte mais visível desta problemática. Ao perspectivarmos o futuro, tanto de um âmbito político quanto do acadêmico, as circunstâncias mostram-se cada vez mais preocupantes e precisam ser enfrentadas coletivamente.

Compreendemos que tal situação não se constitui de eventos meramente "naturais", ainda que estejam ligados a natureza e seus elementos; são construções civilizatórias que se acirraram na modernidade. Com Leff (2001, p.60) encontramos algumas indicações de que "uma das principais causas da problemática ambiental foi atribuída ao processo histórico do qual emerge a ciência moderna e a revolução industrial." Na mesma direção, indicam Inácio e Marinho (2007), ao afirmarem que os problemas ambientais são fruto de processos abrangentes que englobam as dimensões produtiva, política, social e a própria cultura, numa dinâmica de construcionismo social.

Há algumas décadas discute-se que a ciência tradicional temse mostrado insuficiente ao lidar com as questões socioambientais, sobretudo por suas características fragmentária e linear, as quais não permitem enfrentá-los adequadamente em toda sua complexidade. Observa-se a necessidade de fundar uma concepção que inclua, em toda a sua complexidade, as interações entre o conjunto da sociedade, da vida de cada indivíduo e da natureza. Este processo implica em construir uma articulação entre os diferentes campos científicos, considerando os "processos naturais e sociais de diferentes ordens de materialidade", incluindo-se neste processo uma reflexão acerca de suas bases epistemológicas e ontológicas de seus conhecimentos produzidos, com vistas à construção de uma "racionalidade ambiental". (LEFF, 2001, p. 60).

Brügger (1998, p.63), nos diz que "Poluição, extinção e mau uso dos recursos naturais são, sobretudo sintomas - assim como a febre é um sintoma, e não uma doença - de uma crise maior: a crise de paradigma e de civilização (...)"; o que nos leva a compreender que a crise socioambiental é conseqüência de relações de produção e de uma visão de mundo constituidas ao longo do processo civilizatório.

As alternativas à crise [ambiental] compõem um vasto conjunto de ações que vêm sendo testadas em diversas partes do globo ao 
longo das últimas décadas, mediante políticas públicas e setoriais, além de iniciativas de organizações nãogovernamentais, desde associações comunitárias de bairro até instituições de esferas transnacionais como a ONU. Unem-se a essas iniciativas, esforços acadêmicos no sentido da crítica aos modelos tradicionais e hegemônicos e na indicação de outras vias, socialmente mais justas e ambientalmente mais equilibradas como, por exemplo, o 'ecodesenvolvimento' (VIEIRA e WEBER, 1997; HANNIGAM, 1995; LEFF, 2000; CARRIERE e CAZELLA, 2006).

Frente a estas circunstâncias, a escola, tal como outras instituições sociais, precisa rever sua própria trajetória histórica e sua configuração atual, como condição para um enfrentamento da temática. Como instituição, deve constituir-se como um projeto histórico que caminhe nesta direção da "transformação da sociedade e da escola e não a mera otimização do status quo", como nos diz Freitas (2004, p. 133).

Dentre os componentes da escola, encontra-se a Educação Física que, por sua condição de componente curricular obrigatório presente em toda Educação Básica, pode e deve participar deste processo, inclusive por partilhar da forte raiz cartesiana, a qual se encontra dentre os principais problemas identificados na ciência tradicional.

\section{Algumas indicações acerca da educação ambiental}

Com a finalidade de contribuir para a intervenção pedagógica em Educação Física na temática ambiental, compreendemos que a trajetória e reflexões acumuladas pela educação ambiental podem fornecer indicações interessantes que auxiliem nessa tarefa. A relação entre a Educação Física e a questão ambiental, sob perspectivas diversas, incluindo-se a própria educação ambiental, tem sido debatida por vários autores da área, conforme demonstrou Inácio (2006).

A educação ambiental vem constituindo-se como campo de atuação de característica interdisciplinar, assim como o é a produção do conhecimento que lhe fornece o substrato teórico-metodológico. Ainda que constituida a partir da lógica da ciência tradicional, a perspectiva interdisciplinar possibilita superar certo artificialismo e fragmentação presentes no processo de escolarização e na prática pedagógica disciplinar.

Em princípio, compreendemos a educação ambiental não como uma disciplina curricular, mas sim como um tema transversal. Tal possibilidade, aparentemente, poderia dificultar seu processo de desenvolvimento, porém, também permite 
a construção de outra lógica no processo de ensino-aprendizagem.

Observamos a existência de uma política de educação ambiental, especialmente incentivada pelos Parâmetros Curriculares Nacionais do Ensino Fundamental e Médio, o que não vem se mostrando suficiente para garantir a efetivação da educação ambiental nos currículos oficiais. O conhecimento, os procedimentos teórico-metodológicos e a formação de professores são elementos indispensáveis para a realização desta caminhada; elementos estes, porém, que a licenciatura em Educação Física, em geral, não aborda.

O campo aberto pela e para uma educação ambiental, porém, é muito mais amplo do que se apresenta na mídia. Este campo acena para a possibilidade de integrarmos em nossa prática pedagógica, o trabalho sobre uma questão fundamental do humano de hoje: a sua fragmentação e gradativo distanciamento/separação da natureza. A ruptura entre o gesto e a fala, o corpo e o espírito, o humano e a natureza, entre tantas outras divisões, conduzem a uma relação de descontentamento e ausência de reconhecimento a pertença do ser humano à esfera da natureza.

Uma análise da educação ambiental mostra diferentes tendências e perspectivas, a partir das categorias que a constituem.
Estas perspectivas não são necessariamente excludentes entre si e podem ser identificadas, de acordo com Telles (2002, p. 41), em cinco categorias, a saber:

Educação Ambiental Conservacionista - Excursões, lutas conservacionistas, preservação da fauna e flora, para conservação da biodiversidade. Educação Ambiental Biológica - Ênfase na biologia e ciências nos livros didáticos, cadeias alimentares e aspectos da biosfera. Educação Ambiental Comemorativa - Destaca campanhas temporárias, como Comemoração da Semana do Meio Ambiente, etc. Educação Ambiental Política - Vinculação a questões de natureza política, em detrimento dos aspectos naturais. Educação Ambiental Crítica Para Sociedades Sustentáveis - Entendimento das origens, causas e conseqüências de degradação ambiental, por meio de uma metodologia interdisciplinar, visando a uma nova forma de vida coletiva (grifo nosso).

Em nossa perspectiva, a última das categorias citadas constituise como um princípio importante 
para a intervenção pedagógica em Educação Física na temática ambiental. Isto porque propomos uma educação que se contraponha a visão instrumental de natureza que se assemelha ao que Brügger (2004) chama de "adestramento ambiental". Um processo de ensinoaprendizagem em que educadores e educandos encontrem-se estimulados a uma reflexão crítica e ética sobre os valores intrínsecos a natureza e a si mesmos como parte desta, para além da conservação dos recursos naturais, apenas por ser condição para a manutenção da existência humana.

Apesar deste 'avanço' indicado por essa quinta categoria, a proposta de uma educação ambiental crítica para sociedades sustentáveis, nos remete a refletir sobre o conceito de sustentabilidade. Esse conceito foi disseminado, especialmente, na expressão 'desenvolvimento sustentável', a qual aparece pela primeira vez no Relatório Brundtland (1987), originado na la. Conferência Mundial sobre o meio ambiente realizada em Estocolmo (1972) e das indicações do Clube de Roma ${ }^{4}$ INÁClO, 2007).

O conceito de desenvolvimento sustentável ali enunciado preconiza a satisfação das necessidades da geração atual, levando em conta as necessidades das gerações futuras. Essa definição tem sido suficientemente ampla para acolher tanto os adeptos de uma abordagem menos restritiva do desenvolvimento, como aqueles que defendem uma conservação mais estrita da natureza e outros modelos de desenvolvimento que não os tradicionais.

Por isso mesmo, tal conceito de sustentabilidade, estabelecido numa visão instrumental da natureza, explicita uma tentativa da "maquiagem verde" (BRÜGGER, et. al., 2003), por meio da qual é passada uma imagem de que empresas e/ou governos estão preocupados com o meio ambiente, mas, nas entrelinhas, a visão instrumental da natureza continua direcionando ações e atitudes: enquanto os prejuízos da destruição do mundo são distribuídos a todos os seres da natureza, os lucros são restritos a uma minoria da população. Sustentar essa visão técnica, fragmentada da natureza e do conhecimento pode ser chamado de sustentabilidade?

Em direção diferente, constituiu-se outro enfoque, menos disseminado e apresentado também

4 Relatório Brundtland é o documento intitulado Nosso Futuro Comum, publicado originalmente em 1987. Já o Clube de Roma, é uma associação fundada em 1968, reunindo especialistas de todo o mundo para discutir diversos temas em nível mundial, com destaque para a questão ambiental. 
no início da década de 1970 pelo economista francês Ignacy Sachs - o 'ecodesenvolvimento'. Em seu formato original, esse enfoque incorporou alguns conceitos até então marginalizados no debate sobre o fenômeno do desenvolvimento que indicava algumas de suas características: a endogeneidade, a auto-confiança (self-reliance) e a prudência ecológica (INÁCIO, 2003) ${ }^{5}$.

Uma educação ambiental que se encaminhe na direção do ecodesenvolvimento propõe-se a contribuir com princípios teóricometodológicos que oportunizem a reflexão sobre tais questões e, mais especialmente, a experiência pedagógica nessa temática e junto a natureza; uma educação que trate desses temas e que possibilite muito mais o prazer do que normas a aprender.

Dale (apud TELLES et al, 2002, p.42), em meados dos anos de 1950 já "enfatiza que o ensino puramente teórico (simbólico abstrato) deve ser evitado. O imediatamente vivencial permite uma aprendizagem mais efetiva", sobretudo quando pensamos na educação de crianças e jovens. Não há melhor maneira de aprender do que brincando, do que fazendo 'arte'; o brincar é uma oportunidade criativa para o encontro consigo mesmo, com os outros e com o mundo.

$\mathrm{O}$ que se quer construir é uma educação que permita a experiência do corpomundo ${ }^{6}$, em especial, por meio da arte e do lúdico; uma educação da sensibilidade juntamente com a apropriação do conhecimento já produzido e com o desenvolvimento de habilidades. Para tanto, é necessário preocupar-se tanto com o processo quanto com o produto final; além do conhecimento, a ação, a atitude e seus significados. É nesta perspectiva que compreendemos que artista e educador podem aproximar-se em sua singularidade e na especificidade de sua contribuição social, como aqueles que propõem - como diz Morais (2001, p.169), "situações que devem ser vividas, experimentadas".

\section{Construindo outro caminho para a educação física: elemen- tos teórico-metodológicos ou 'a sedimentação do solo'...}

A proposta de construir outro caminho teórico-metodológico para a Educação Física compreende o corpo humano não numa

5 Não é intenção deste ensaio debater os modelos e enfoques de desenvolvimento. Para saber mais sobre o ecodesenvolvimento consultar Vieira e Weber, 1997 e Sachs, 1995.

6 Expressão que indica esse encontro sensível entre o ser humano e o ambiente, em especial com a natureza, criada e melhor desenvolvida na dissertação de mestrado de Weber (2007). 
perspectiva biologicista, de forma isolada e a-histórica, mas sim a partir das imbricadas relações que estabelece com seu entorno e com o mundo. Acompanhados dessas inquietações, buscamos explorar alguns elementos para uma experiência pedagógica em Educação Física na temática ambiental, que se contraponha a perspectiva tradicional fundada no treinamento de habilidades ou para a aptidão física, a qual ainda prevalece nesta disciplina curricular.

Inácio e Marinho (2007), concordando com Melo et al. (2007), indicam que a Educação Física pode se valer das experiências na natureza como possibilidade pedagógica, numa forma de educação ambiental voltada a professores de educação física; denominada "expressividades do corpomundo"
(Melo et al. 2007, p. 25). Essa proposta, mais que apresentar conteúdos clássicos da educação ambiental, busca 'ecologizar' a formação dos professores.

A expressão corpomundo, acima mencionada, sintetiza boa parte dos princípios ontológicos que nos mobilizam e subsidiam os elementos para uma ressignificação da experiência pedagógica. $\mathrm{O}$ processo de construção da consciência e da percepção corporal, da corporalidade, implica também na ressignificação do próprio entendimento e das interações entre ser humano e natureza, no momento em que procuramos tornar mais explícita a complexidade própria às relações entre as dimensões internas (natureza orgânica) e externas (natureza inorgânica), como nos indicava Marx (1989).

HUNDERTWASSER. As cinco peles do Homem.

Desenho a tinta, 29,7 x 20,9 cm, Viena,

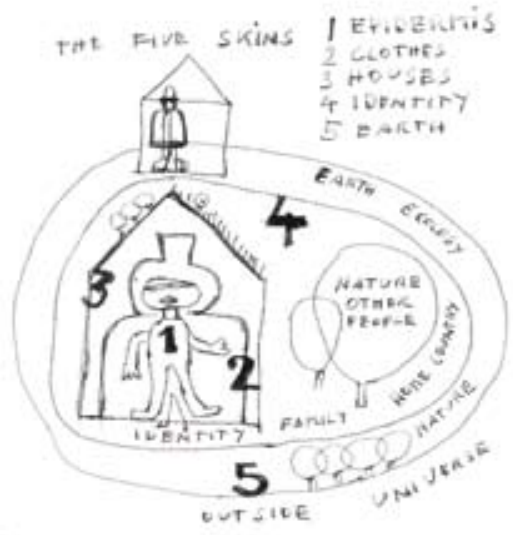


Para subsidiar a ressignificação da experiência pedagógica trazemos uma referência do mundo das artes, a concepção metafórica de corpo 'multiepidérmico' sugerida, desenhada e vivenciada pelo pintor e arquiteto austríaco Friedensreich Hundertwasser em suas criações. A obra desta artista nos auxiliou na constituição destes elementos teórico-metodológicos, sobretudo pela forma como concebe o corpo humano em suas dimensões interiores e exteriores, mas também por aquilo que subsidia na estruturação das temáticas de trabalho.

Hundertwasser concebe um corpo-humano de cinco peles, tal como nos mostra o esboço ao lado ${ }^{7}$. As cinco peles seriam a epiderme, a vestimenta, a casa, as relações sociais e a natureza, constituindo-se como diferentes níveis de compreensão e percepção que o ser humano possui de sua própria existência.

Um projeto educacional poderia construir possibilidades de reflexão e de ação deste corpo multiepidérmico, sobretudo ao lidar com a temática ambiental. Um corpo com cinco peles e que tenha a lentidão como escolha, não menosprezando a velocidade, mas sim numa tentativa de ressignificar a própria fruição da experiência estética.
Contrapor a lentidão à velocidade que prevalece no cotidiano significa enfrentar um processo de coisificação do corpo e do tempo e se encaminhar para uma relação de emancipação e autonomia com a diversidade rítmica do mundo.

Conceber um corpo com tais dimensões, texturas e velocidades, talvez não seja possível por meio dessa racionalidade hegemônica que nos é imposta na modernidade; mas, sim, pela inclusão da dimensão sensível que nos faz presentes em nossa corporalidade e que pode ser mais bem aguçada por uma educação dos sentidos, uma educação estética. O corpo, nessa concepção, não é

(...) dominado e esquadrinhado por retas e vetores de um racionalismo eficaz, mas sim um corpo que se contorce em seu interior, e justamente daí retira suas forças para desenrolarse em espiral. (...) permitindo constituir-se por dimensões daquilo que lhe é estrangeiro. Uma pele que germina em um movimento profundo admitindo e captando matizes da alteridade na configuração de sua própria consciência. (PERETTA, 2005, p.128-129)

7 HUNDERTWASSER. As cinco peles do Homem. Desenho a tinta, 29,7 x 20,9 cm, Viena, 1998. 
Dessa forma, entendemos que para estabelecer as relações de alteridade que se fazem presentes no corpo das cinco peles, há a necessidade de constituir outro processo educacional que propicie uma aptidão à experiência (ADORNO, 2003), envolvendo as sutilezas da natureza humana. A experiência pedagógica que buscamos explorar perpassa as cinco peles de forma sutil e prazerosa, e uma espiral que se amplia gradativamente.

Cornell $(1996$; 1997) apresenta uma teoria chamada de "aprendizado seqüencial", a qual contribui para a construção destes elementos teórico-metodológicos que sugerimos no trabalho com a temática ambiental. Dentre outras contribuições de sua teoria, destacamos a ênfase na ludicidade, com alternativas que visam a mudança do comportamento humano junto aos demais e a natureza.

Os jogos e as brincadeiras, em sua condição de prática corporal lúdica, trazem consigo uma possibilidade pedagógica que valoriza ao mesmo tempo o lúdico, a arte, a cooperação, a sensibilização e a aprendizagem que levam a compreensão e conscientização do ser humano em si mesmo e com o seu exterior. O simples contato com a natureza e com essas atividades não é o suficiente, porém, há uma positividade nesse tipo de trabalho com vistas a provocar mudanças na relação da pessoa com o mundo. Os principais componentes dessa experiência pedagógica são o corpo, o colega e o entorno, sem pré-requisitos e sem competição, construida a partir da disponibilidade e abertura para o mundo.

Da perspectiva proposta por Cornell, partilham outros pesquisadores do campo da Educação Física, como é o caso de Marinho (2004, p. 03), ao afirmar que

(...) reconhecer que a simples visita à natureza nem sempre é suficiente para proporcionar aos turistas, visitantes, e aventureiros empatia com outras formas de vida, bem como uma interação pessoal com elas. Daí a importância da proposta de Cornell (1997) referente a um aprendizado seqüencial, o qual é capaz de despertar, sutilmente, a percepção da natureza. (MARINHO, 2004, p.3).

O aprendizado seqüencial é um sistema bastante flexível que proporciona liberdade de acordo com as necessidades do momento, sendo possível ser desenvolvido em qualquer lugar, ao ar livre, na sala de aula ou em diferentes esferas da vida pessoal. "Você também descobrirá que as pessoas participarão com mais entusiasmo de discussões sobre o aspecto científico e da 
ecologia se você primeiro ajudálas a ficar receptivas e inspiradas" (CORNELL, 1997, p.17).

Sua proposta não tem a intenção de estabelecer obrigatoriedade nas condutas a serem tomadas: ao contrário, a intenção é oportunizar possibilidades e estratégias a serem selecionadas pelos educadores, ao organizar uma experiência direta e sensível com a temática ambiental. Não estamos propondo uma educação apenas naturalizada e romântica junto à natureza, mas, sim, uma relação onde a sensibilidade e a racionalidade caminhem juntas, aliando conhecimento, percepção e emoção.

A perspectiva do "aprendizado sequencial" divide-se em quatro estágios, segundo o quadro apresentado por Cornell (1997, p. 46):

O primeiro estágio, intitulado "despertar o entusiasmo" é identificado como um estágio ativo, onde as vivências divertidas despertam a alegria e o entusiasmo de participar dos momentos seguintes. Torna-se, assim, uma introdução às experiências pedagógicas mais profundamente enraizadas e de maior sensibilidade. É um estágio importante porque indica o caminho que vai ser desenvolvido, estimulando o grupo a um objetivo considerado central que é agir cooperativamente. Apenas com este princípio é possível entregar-se ao momento e se permitir a experiência. Com isto, também, pode-se "mudar o botão", metáfora utilizada por Mendonça (2000, p.144), para exemplificar outro objetivo deste estágio, reforçando a necessidade de vivenciarmos sensibilidades/ sensações diferenciadas daquelas às quais estamos acostumados em nosso cotidiano, destacando a importância desse estágio para o sucesso dos seguintes.

O segundo - "concentrar a atenção", é, para Cornell (1996), momento em que se deve concentrar a intencionalidade e energia produzidas na etapa anterior, tornando o grupo mais calmo e receptivo. Caracteriza-se como uma travessia entre as vivências mais agitadas para aquelas mais reflexivas, as quais necessitam maior concentração. É nesse momento que se inicia, ainda que de forma sutil, as experiências

\begin{tabular}{|l|l|}
\hline \multicolumn{1}{|c|}{ ESTÁGIOS } & \multicolumn{1}{c|}{ QUALIDADES } \\
\hline Despertar o entusiasmo & Divertimento e vivacidade \\
\hline Concentrar a Atenção & Receptividade \\
\hline Dirigir a experiência & Absorção \\
\hline Compartilhar a inspiração & Idealismo \\
\hline
\end{tabular}


mais sensíveis, desenvolvendo e aguçando os sentidos e a expressão de outras percepções estimuladas pelo entusiasmo que caracteriza o estágio anterior - momento no qual buscamos o refinamento da atenção mais seletiva e direcionada ao foco de nossa atividade; "é nesse momento em que a diferença entre o olhar e ver" (MENDONÇA, 2000, p.145) vai ser evidenciada numa aproximação à experiência.

O terceiro estágio - "dirigir a experiência" - apresenta semelhanças com o anterior, porém, as atividades deste estágio devem envolver de forma mais direta os sujeitos nos elementos da natureza. É onde se constitui melhor a possibilidade de fruição das experiências estéticas, como discutiu Silva (2007). Neste momento, a imersão na experiência permite abrir-se a outras realidades, ampliando a percepção do mundo que nos rodeia e a construção e reconhecimento do corpomundo. Proporciona uma experiência mais direta na interação dialética entre humano e natureza onde o tempo pode apresentar-se de outra maneira e a preocupação com desempenho ou qualquer tipo de competição não se faz presente.

Por fim, o quarto estágio é aquele que se caracteriza por "compartilhar a inspiração". Estágio este em que a reflexão se faz presente e, por meio de atividades mais simples, busca-se um encerramento das experiências que favoreça uma percepção mais ampliada da totalidade. É um momento significativo para os depoimentos sobre as experiências vivenciadas nos estágios anteriores, acessando imagens, memórias, sensações, percepções ao nível mais consciente e racional, compartilhando-as com os demais como possibilidade de ampliação de sua própria experiência.

Esses estágios possibilitam uma forma de organização do tempo pedagógico, tomando como base e ampliando a contribuição feita por Cornell $(1996,1997)$. Além disso, na perspectiva educacional que queremos construir, a experiência pedagógica é permeada pela dimensão artística e esta deve contextualizar-se no momento social emergente, procurando sensibilizar para as mudanças de atitudes e hábitos necessários ao tempo e à época. Isto é, refletir sobre os problemas sociais, econômicos e ambientais contemporâneos e sobre as possíveis contribuições da arte.

Um exemplo disso é a utilização de materiais recicláveis ${ }^{8}$ nessas

8 O fato de reciclarmos, por si só, não assegura uma contraposição à lógica consumista; porém, a educação ambiental nos indica a importante lição dos três R's: Reduzir, Reutilizar e Reciclar, como um caminho para isso. 
atividades como uma das possibilidades de se contrapor à lógica consumista. Além disso, incentivar a vivência da cooperação e da construção e não da competição, deixando de lado a idéia do 'mais belo', do 'mais perfeito'. Sempre que possível, buscar a produção coletiva, mesmo que isso se dê com a junção das partes ao final, formando um todo passível de maior reflexão pelo grupo.

Estamos falando da atividade artística numa concepção que se aproxima do lúdico, expressões humanas que se complementam, se retroalimentam e se confundem. Expressões que não estão alienadas do mundo, mas que se opõem à sua visão hegemônica, com sentimentos de espontaneidade que valorizam o processo e não o produto final, com ênfase na cooperação e não produtividade. Expressões que se dão pelo contato corporal e direto com o mundo, com a natureza, e que aguçam a percepção de outras experiências estéticas, como nos diz Cornell (1996, p. 04):

(...) cada brincadeira cria uma situação, ou uma experiência, na qual a natureza é a mestra. Cada uma delas representa uma boca por meio da qual a natureza fala - algumas vezes na linguagem do cientista, outras na linguagem do artista ou na linguagem mística.
A arte de brincar com o corpomundo fundamenta-se numa perspectiva estética que busca uma relação mais próxima com os seres e elementos da natureza construindo uma qualidade de experiência que não se mostra possível junto aos ambientes urbanos. Quando entramos em contato com a terra, chuva, sol, elementos marinhos, texturas, sons, os corpos humanos, podemos despertar sentidos muitas vezes adormecidos, como o tato mais sensível, o olfato apurado, a audição seletiva, a visão mais abrangente. Podemos perceber em cada elemento natural, seus cheiros, texturas, temperaturas, sonoridades, ritmos e cores e suas diferentes possibilidades de interação nos ciclos ao longo dos dias e das estações.

Nesse sentido, argumentamos por uma formação que não se basta somente no próprio educador, no estudante ou mesmo na instituição escolar. Uma formação que busca privilegiar as diferentes relações estabelecidas num contexto socioambiental mais amplo e a qual pode ser chamada de formação ecológica.

Essa formação ecológica ultrapassa uma visão romântica da natureza, apaixonada por ambientes naturais e preocupado com a conservação da fauna e flora. Constituise mais como uma compreensão de totalidade por meio da articulação e diálogo daquilo que Guattari (1990) 
identifica como os três registros ecológicos: o da subjetividade humana, o das relações sociais e o do meio ambiente.

No primeiro registro que trata da "ecologia da subjetividade", a preocupação com o cuidado de si parte de uma reflexão crítica acerca da forma como vem sendo elaborada essa imagem de corpo idealizada e de formação humana que se mostra alienada e massificada. Apontaria para uma necessidade da ressignificação da construção subjetiva, onde o trato consigo mesmo é privilegiado no fundamental ato de ser-sujeito do próprio processo. Entretanto, na relação com a "ecologia social", as relações de cuidado consigo mesmo se ampliam para o cuidado com o outro, primando pela cooperação e respeito ao espaço do outro, com vistas a construir e compor uma sociedade ecodesenvolvida. Ao habitarmos o mesmo ambiente, nesse aqui e agora, há que considerar como princípio ético o cuidado com o terceiro registro: a "ecologia ambiental". Essa ecologia representa justamente a dimensão ambiental, onde não apenas se privilegiam os ambientes naturais, mas também os sociais e subjetivos; todos como pertencentes e em constante relação na construção da 'comum-unidade'.

Uma possibilidade teórico-metodológica que estabelece grande interface com esses elementos indicados acima são os núcleos geradores das "expressividades do corpomundo" (MELO et all, 2007). ${ }^{9}$ Com inspiração na obra de Freire (1983), a finalidade principal dos núcleos geradores seria fomentar a reflexão sobre temas de maiores abrangência e emergência na sociedade atual, assim como de aproximação com o cotidiano do grupo onde está presente, mais explicitamente, a relação ser humano - natureza. Os três núcleos geradores, por sua articulação com as diferentes ecologias ou "peles", possibilitariam um nível mais ampliado de consciência como parte de um processo de formação humana.

1) Cuidado de si: uma aproximação das três primeiras peles do humano com a ecologia subjetiva,

9. Destacamos, sobre este tema, a dissertação de Peretta (2005), da qual, inclusive, foi tomada de empréstimo a expressão "Nua natura" que dá nome a um dos núcleos geradores. Essa perspectiva pedagógica foi experimentada em curso de formação continuada, com este mesmo título grifado, desenvolvido com professores de várias áreas da Rede Estadual de Ensino de Santa Catarina, bem como com alguns provenientes de escolas privadas, como parte de um projeto da Rede CEDES/ UFSC, cujo relatório encontra-se publicado em FALCÃO, J. L. C. SARAIVA, M. do C. (org). Esporte e lazer na cidade: práticas corporais re-significadas. V.1 Florianópolis: Lagoa Editora, 2007. 200 p., e em FALCÃO, J. L. C. SARAIVA, M. do C. (org). Esporte e lazer na cidade: a prática teorizada e a teoria praticada. V.2 Florianópolis: Lagoa Editora, 2007. 172 p. 
construindo de forma sensível um maior contato do indivíduo com suas potencialidades de expressão e percepção. Nesse núcleo gerador, podemos trabalhar diferentes formas de sensibilização e expressão corporal como massagem, meditação, relaxamento e exercícios cênicos.

2) Nós na teia: detêm-se com mais atenção na quarta pele e na ecologia social, buscando ampliar a percepção da dimensão coletiva que compõe a existência de cada ser humano. A partir de práticas corporais lúdicas, da musicalidade, das experiências cooperativas e cênicas busca-se expor uma concepção sistêmica e ecológica para compreender algumas das relações da complexa teia da vida.

3) Nua natura: proposta de imersão profunda e sensível na quinta pele do humano e da ecologia ambiental. A partir de experiências estéticas e lúdicas, a proposta é um contato direto com o ambiente natural e suas singularidades por meio da teoria do "aprendizado seqüencial" de Cornell $(1996,1997)$, potencializando, assim, a percepção sensível dessa pele planetária compartilhada por todos os seres vivos.

Os núcleos geradores, tal como os demais elementos teórico-metodológicos indicados anteriormente, buscam construir uma experiência pedagógica na qual sujeito e objeto momentanea- mente se confundem, como indica Sant'Anna (2001); quando ação, paixão e imaginação se entrelaçam mais profundamente, estabelecendo uma composição entre a brincadeira, o brinquedo e o brincante.

Alertamos, porém, que essas proposições teórico-metodológicas pouco auxiliam se não forem acompanhadas de permanente inquietação e autoavaliação crítica: como desenvolver o cuidado de si? Como estabelecer relações mais profundas e emancipatórias com o que nos cerca, superando a competição e os diferentes tipos de preconceito, as atitudes antropocêntricos, comportamentos esses tão disseminados na atualidade e enraizados em cada um de nós? Questões que devem nos acompanhar tanto na intervenção pedagógica quanto na vida.

\section{O Caminho se faz ao cami- nhar...}

Com esse texto, nossa intenção foi contribuir para a construção de elementos teórico-metodológicos - ou de outro caminho para a Educação Física - tendo a temática ambiental como um eixo transversal. A Educação Física escolar pode e deve continuar trabalhando com seus conteúdos tradicionais, como a dança, a ginástica, o esporte, as lutas e acrobacias. Pode, além disso, incluir as práticas corporais 
de aventura na natureza como parte da experiência pedagógica o que contribuiria para com uma formação humana mais ampliada, tematizando questões fundamentais frente à crise socioambiental.

Esses elementos podem, ainda, permear o trabalho com estes outros conteúdos, contrapondo-se a uma perspectiva esportivizada e esportivizante que ainda prevalece na Educação Física atual. A experiência pedagógica junto à natureza propicia uma educação da sensibilidade e uma ampliação da percepção e imaginação acerca do mundo, permite uma reflexão crítica da realidade vivenciada, e mais nos mobiliza e impulsiona na busca por caminhos para sua superação.

\section{Referências}

ADORNO, T. Trad. Wolfgang Leo Maar. In: Educação e emancipação. Rio de Janeiro: Paz e Terra, 2003.

BRÜGGER，P. Educação ou adestramento ambiental? 3. ed. Florianópolis/ Chapecó: Letras Contemporâneas/ Argos Editora Universitária, 2004. v. 1500. $200 \mathrm{p}$.

BRÜGGER, P. Maquiagem verde: a estratégia das transnacionais versus a sustentabilidade real. In: GUIMARÃES, L. BRÜGGER, P. de SOUZA, S. C. de Arruda, V. L.
V. (Org.). Tecendo subjetividades em educação e meio ambiente. $1^{\text {a }}$ ed. Florianópolis: NUP/CED UFSC, 2003, v. 6, p. 159-170.

BRÜGGER, P. Visões estreitas na educação ambiental. Ciência Hoje, Rio de Janeiro, v. 24, n.141, 1998.

CARRIÈRE, J.P. CAZELLA, A. A. Abordagem introdutória ao conceito de desenvolvimento territorial. In: ESFORIA. Revista do Programa de Pós-Graduação em Agroecossistemas/UFSC. V.4, $\mathrm{n}^{\circ}$ especial, p.23-47, 2006.

C OMISS ÃO MUNDIA L SOBRE MEIO AMBIENTE E DESENVOLVIMENTO. Nosso Futuro Comum. Rio de Janeiro : Editora da Fundação Getulio Vargas, 1988.

CORNELL, J. A alegria de aprender com a natureza para todas as idades. São Paulo: SENAC; Companhia Melhoramentos, 1997.

CORNELL, J. Brincar e aprender com a natureza: um guia sobre a natureza para pais e professores. São Paulo: SENAC; Companhia Melhoramentos, 1996.

FREIRE, P. Educação como prática da liberdade. Rio de Janeiro: Paz e Terra, 1983.

FREITAS, L. C. A avaliação e as reformas dos anos de 1990: novas formas de exclusão, velhas formas de subordinação. In: 
Revista Educação e Sociedade. Campinas, vol. 25, n. 86, p. 133170, abril 2004

GUATARRI, F. As três ecologias.

Campinas: Papirus, 1990.

HANNIGAN, J. A. Sociologia ambiental. Lisboa: Instituto Piaget, 1995.

INÁCIO, Humberto Luís de Deus. $\mathrm{O}$ ecoturismo como vetor do desenvolvimento territorial sustentável: um estudo de caso no Alto Vale do Itajaí. 2007. 240

f. Tese (doutorado em Sociologia Política) - Programa de Pósgraduação em Sociologia Política, Universidade Federal de Santa Catarina, Florianópolis, 2007.

INÁCIO, H. L. D. MARINHO, A. Educação física, meio ambiente e aventura: um percurso por vias instigantes. Revista Brasileira de Ciências do Esporte. V.28, $\mathrm{n}^{\circ} 3$, p.55-70, 2007.

INÁCIO, H. L. D. Lazer, educação e meio ambiente: uma aventura em construção. Revista Pensar a Prática. V.9, nº1, p.45-63, 2006. I NÁClO, H. L. D.

Ecodesenvolvimento e turismo: bases para uma outra relação com o planeta. EmTese - Revista Eletrônica dos Pós-Graduandos em Sociologia Política da UFSC. V. 1, no 1 (1), p. 169-188, agostodezembro/2003.

LEFF, H. Epistemologia ambiental.

São Paulo: Cortez, 2001.
LEFF, H. Ecologia, capital e cultura: racionalidade ambiental, democracia participativa e desenvolvimento sustentável. Blumenau: Ed. da FURB, 2000. MARINHO, A. O lúdico e a natureza. In: Encontro da Associação Nacional De Pós-Graduação e Pesquisa em ambiente e sociedade, 2, 2004, Indaiatuba. Anais... Indaiatuba, ANPPAS, 2004.

MARX, K. O trabalho alienado. In: MARX, K. Manuscritos econômico-filosóficos. Lisboa: Edições 70, 1989. p. 157-172.

MELO, C. K. de. et al. Educação do corpomundo. Princípios éticos, estéticos e ecológicos no fortalecimento da sensibilidade humana. In: FALCAO, J. L. C.; SARAIVA, M. C. Práticas corporais resignificadas. Florianópolis: Lagoa Editora, 2007, vol. 01, p. 115-141.

MENDONÇA, R. A experiência na natureza segundo Joseph Cornell. In: SERRANO, C. (Org.). A Educação pelas pedras: ecoturismo e educação ambiental. São Paulo: Chronos, 2000. 135-154.

MORAIS, F. Contra a arte afluente: o corpo é o motor da obra. In: BASBAUM, R. (Org.) Arte contemporânea brasileira: texturas, dicções, ficções, estratégica. Rio de Janeiro: rios ambiciosas, 2001. 
PERETTA, E. S. Alteridades da pele, fronteiras do corpo. 2005. 155

f. Dissertação (Mestrado em Educação Física) - Programa de Pós-Graduação em Educação Física. Centros de Desportos, Universidade Federal de Santa Catarina, 2005.

SACHS, I. Em busca de novas estratégias de desenvolvimento. In: Estudos Avançados, 9(25), 1995.

SANT'ANNA, D. B. Corpos de passagem: ensaios sobre a subjetividade contemporânea. São Paulo: Estação Liberdade, 2001.
SILVA, A. M. Das relações estéticas com a natureza. Revista Brasileira de Ciências do Esporte. V. 28, p. 141-156, 2007.

TELLES, M. Q. et al. Vivências integradas com o meio ambiente. São Paulo: Sá Editora, 2002.

VIEIRA, Paulo H. F. WEBER, Jacques. (orgs.) Gestão de recursos naturais renováveis $\mathrm{e}$ desenvolvimento. Novos desafios para e pesquisa ambiental. São Paulo: Cortez, 1997.

Recebido: 30/agosto/2009 Aprovado: 20/outubro/2009 